Research Article

\title{
An Evolutionary Game Model on Public Participation in Public-Private Partnerships
}

\author{
Danrong Song, ${ }^{1}$ Yan Sun $\mathbb{D D}^{2}$ and Yu Fan ${ }^{1}$ \\ ${ }^{1}$ School of Business Administration, University of Science and Technology Liaoning, Anshan 114051, China \\ ${ }^{2}$ Faculty of Humanities and Social Sciences, Dalian University of Technology, Dalian 116023, China \\ Correspondence should be addressed to Yan Sun; sunyan@dlut.edu.cn
}

Received 3 July 2020; Revised 18 November 2020; Accepted 3 December 2020; Published 24 December 2020

Academic Editor: Antonio Formisano

Copyright $(92020$ Danrong Song et al. This is an open access article distributed under the Creative Commons Attribution License, which permits unrestricted use, distribution, and reproduction in any medium, provided the original work is properly cited.

Effective participation of the general public in public-private partnerships (PPPs) can coordinate the multidemands of stakeholders and improve the scientificity of decision-making on infrastructure and public utility projects. However, excessive public participation may aggravate the complexity of PPPs and delay the progress of developing PPP projects. Accordingly, the appropriate participation of the general public is essential in the implementation of PPPs. This study examines the boundary conditions and the effective thresholds of public participation in adjusting the cooperative behaviors of both the government and the private investor in PPPs through an analysis of the evolution paths and dynamic balances of the strategy choices between the two parties. The results indicate that public participation in PPPs has the particularity of adjusting the partnership between the two parties. The results also suggest that public participation is not always effective and there are differences in the degree of public participation in the various strategy behaviors in which the government and the private investor choose to cooperate.

\section{Introduction}

Public-private partnerships (PPPs) are defined as the cooperation between the government (or the public authority) and the private investor to improve public service delivery and realize the provisions of infrastructure [1-3]. The government holds the administrative and policy-making powers. The private investor is responsible for the design, construction, operation, and maintenance of a PPP project within the scope of the PPP agreements and policy constraints. The government and the private investor are two direct participants who receive respective advantages from their collaborations. In addition, as recipients of public service or end users of infrastructure in PPP projects, the general public is the ultimate beneficiary and proposes some demands to the relevant government and receives public service or production provided by the private investor. Although the general public is an indirect participant in PPP agreements and decision-makings, its supervision and evaluation affect the healthy development of the PPPs [4-6].
If communication with the general public is inadequate or if the interests of the general public are ignored, it will lead to strong public opposition and result in the relocation, suspension, or even termination of PPP projects $[7,8]$. Consequently, great losses will be brought to the whole society. Many failed cases, such as the Hangzhou Bay Cross-sea Bridge in China, the Tokyo Waste Incineration Power Plant in Japan, the Skye Island Bridge Project in UK, the Ontario Medical Program in Canada, and the Hazardous Waste Treatment Project in Yuma County, Ariz., USA [9-11], reveal the serious consequences of the lack of public participation or inappropriate public participation in PPP projects. Furthermore, there are problems, in practice, with public participation in the PPPs, such as insufficient time to allow the general public to participate [12], indirect and passive participation [13], and imperfect laws and regulations [14].

Consequently, there are three main participants in operation of PPPs including the government, the private investor, and the general public. The relationships of the three parties are shown in Figure 1. 


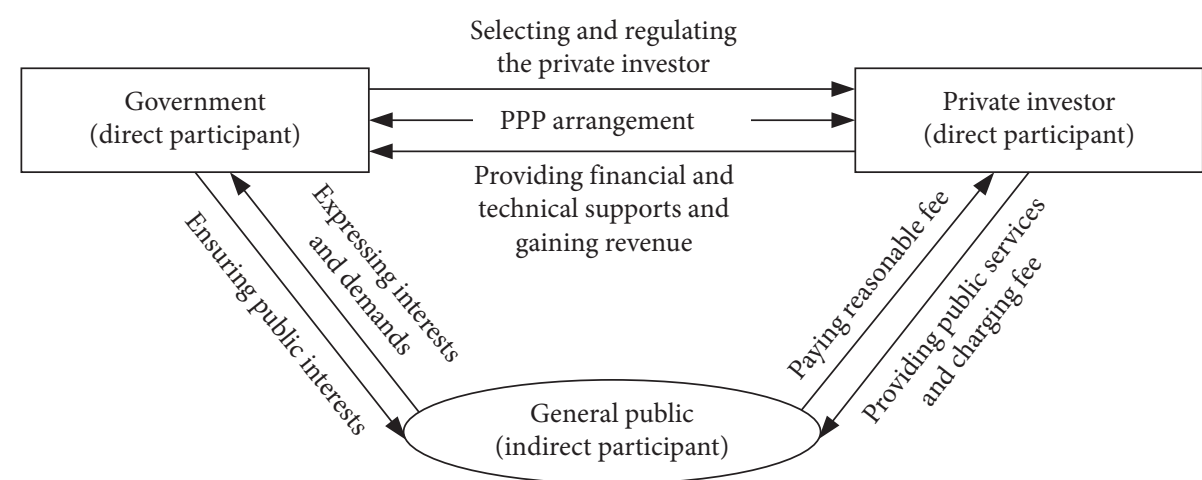

FIGURE 1: The relationships between the government, private investor, and general public.

Most of the existing research studies analyzed the cooperation mechanism in PPPs from the perspectives of the two direct participants, i.e., the government and the private investor. For example, Carbonara and Pellegrino developed a win-win model to calculate the optimal government guarantees for the private sector and the government and to fairly allocate risks between them [15]. Jin et al. presented an effective methodological framework for the probabilistic evaluation of the excess profit allocation between the government and the private investor, as well as the corresponding subsidy mechanism [16]. The study conducted by Liu et al. proposed a two-dimensional framework for evaluating the fiscal support mechanisms by the government to attract private financing [17]. Pellegrino et al. employed real options to discuss the set of the maximum interest rate by which the private investor will obtain reimbursement from the government [18]. However, a few studies have been conducted to investigate the strategic behaviors of the government and the private investor influenced by the participation of the general public in PPPs. It is a complicated issue that involves the interactions between the general public and the government, the general public and the private investor, and the government and the private investor. Therefore, how to promote cooperation between the two direct participants from the perspective of public participation is examined in this paper.

Public participation is an activity that the general public, as a stakeholder, values in the PPP project, as it allows them to claim their rights and express their interests and, thereby, influences decisions made by the government and the private investor on the provision of the public service and productions $[19,20]$. The field has developed a wealth of rich literature on the concepts $[21,22]$, types [23, 24], approaches and mechanisms $[25,26]$ of public participation in environmental protection, urban planning, public policy decision making, and governance. The levels of public participation are divided according to the depth of the activity, and accordingly, there are differences in the ways the general public can participate [27]. While increasing public participation improves satisfaction of the general public and promotes the performance of both the government and the private investor [21], the practical effect of public participation on PPPs remains uncertain [28].
Thus, there are several questions regarding public participation that deserve attention. How do relations between the government and the private sector evolve after the general public participates in a PPP project? What is the requisite degree of effectiveness that the participation of the general public must attain to impact or modify the strategic behaviors of the government and the private investor in PPPs? How can we quantify the reasonable participation of the general public in various situations to achieve a strategic balance between the government and the private investor?

Game theory is a method used to study how decision making and decision-making equilibrium are conducted while interactions among the parties are ongoing [29, 30]. The premise of classic game theory is that the participants are completely rational, a condition that is difficult to achieve in reality. Evolutionary game theory combines the analysis of the game with that of dynamic evolution, and thus, it more accurately reflects the dynamic equilibrium of game behavior among limited rational groups [31-33]. Evolutionary game theory is an important analytical tool that has been widely used in social governance [34-36], government administration [37-39], and business operation and management fields [40, 41]. In practice, it is difficult for the government and the private investor to find equilibrium strategies under uncertain conditions due to information asymmetry and the dynamic changes in the operating environments of PPPs. Hence, as both the two direct participants are bounded by rationality, the strategic choice and equilibrium of the game between them are dynamic processes.

The aim of this study is to construct an evolutionary game model that illustrates the evolution and dynamic equilibrium of collaborative behaviors between the government and the private investor in PPPs and then to analyze the participation of the general public as an indirect influencing factor on the evolutionary equilibrium (as shown in Figure 2). The contribution of this article is that it provides an explanation of the boundary conditions and effective thresholds of the public participation activities that affect the collaborations between the government and the private investor. Moreover, it offers an improved understanding of the degree of public participation in PPPs, which is a variable that must be considered given different situations rather than fixed ones. 


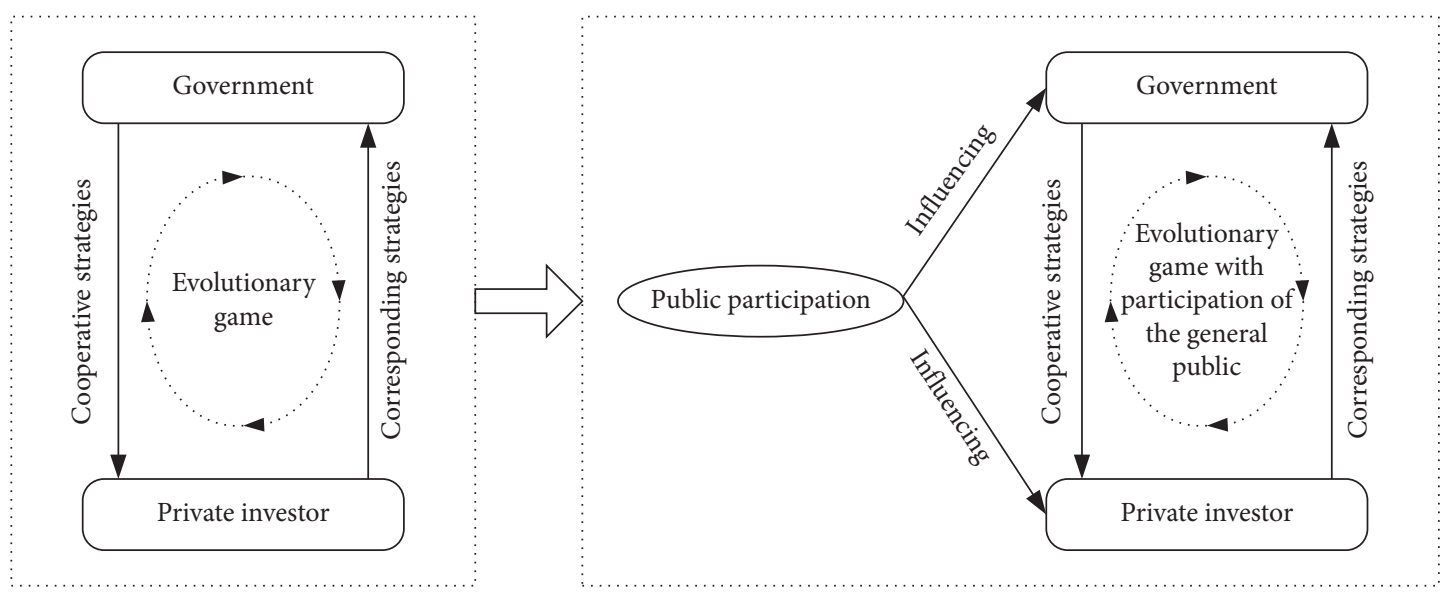

FIgURE 2: The analysis mode of this research.

\section{Game Model Construction}

The government and the private investor are two parties directly involved in the game of PPPs. The subsidies and tax preferences given by the government to the private investor usually depend on the extent to which the government actively cooperates, whereas the level of revenue and public acceptance of the private investor often depend on the quality of the public services/products provided by the private investor. Moreover, there may be conflicts of interest between the two parties, as the former pursues the maximization of the social benefits for the general public and the latter pursues the maximization of its profits.

The participation of the general public helps to balance the power and reduce the contradictions in PPPs [42, 43]. Accordingly, from the perspective of the general public as an indirect participant in the public-private game, the degree of public participation is considered as an influencing factor of the game in this research. When the general public joins in the PPPs, its demands may be expressed and the cooperation strategies of the government and the private investor may be changed. Therefore, this paper supposes that public participation is effective when it has the potential to adjust the evolutionary stable strategies between the two decisionmaking parties.

Based on the aforementioned statements, basic assumptions regarding the evolutionary game model are proposed.

Assumption 1 The individuals in the two game parties, i.e., the government and the private investor, are comprised of bounded rational people. Specifically, the government is composed of government officials who are involved with the PPP project, whereas the private investor is composed of groups, companies, enterprises, and/or consortia who have established partnerships with the government for the construction and operation of the PPP project. In addition, the general public refers to the people with direct or indirect interests in the PPP project, as well as other interested organizations and groups.
Assumption 2

(i) When facing the strategic behaviors of the private investor in PPPs, it is supposed that the government has two strategic choices, i.e., active cooperation (AC) and no active cooperation (NAC). The strategy of AC suggests that the relevant government can actively complete the PPP agreement, e.g., paying subsidies to the private investor on time and actively maintaining the partnership between the two sides to ensure the successful implementation of the PPP project. The strategy of NAC is contrary to that of AC.

(ii) The private investor also has two strategic choices, i.e., to provide high-quality public services/products (PHS) and to provide low-quality public services/ products (PLS). The strategy of PHS suggests that the private investor actively fulfills the PPP agreement and enables the general public to experience better services and products, while the strategy of PLS indicates that the private investor reduces the project investment and reduces the cost of operation and maintenance to improve its own profits without taking the interests of the general public into account.

\section{Assumption 3}

(i) The revenue of the private investor in PPPs includes two parts, namely, income from the project and subsidies/preferences from the relevant government. The former is dependent on the quality of the public services/products provided by the private investor, whereas the latter depends on the cooperative attitude of the government, i.e., those who evaluate the level of efforts and performance of the private investor. Thus, the revenue is represented by four values, $R_{i}(i=1,2,3,4)$, according to the four different situations that are formed from the combination of the strategies of the private investor 
adopting either PHS or PLS and the relevant government adopting the strategy of either AC or NAC.

(ii) When the private investor adopts the PHS strategy, additional time and human and material resources are required. Hence, the resulting additional cost is set to $C$.

(iii) It is assumed that PPP projects promote the efficiency of public services and products and enhance the reputation and performance of the relevant government. Thus, the efficiency of the PPP projects and the evaluations of the relevant government, as drawn from the general public and its leaders, are affected by the quality of the public services and products provided by the private investor and the cooperative attitude of the government toward the PPP projects. Hence, the revenues that the PPP projects bring to the government are set as $G_{i}(i=1$, $2,3,4)$, according to the four situations previously mentioned.

Assumption 4. When the general public is participating in a PPP project, it is supposed that the degree of public participation is $\lambda(0 \leq \lambda \leq 1)$. That is, the participation of the general public in the PPP project improves the revenue of the government that actively cooperates or the private investor that provides PHS, such that the degree of improvement is $\lambda$. Meanwhile, the revenue reduction is $\lambda$ when the government does not actively cooperate or the private investor provides PLS.

As a result, the game payoff matrices between the government and private investor are examined under two scenarios, namely, without and with public participation in PPPs, as presented in Table 1.

\section{Evolutionary Game Analysis}

We suppose that, in the initial stage of the game, the proportions of the private investor adopting the PHS and PLS strategies are $x$ and $1-x$, respectively, and the proportions of the government adopting the AC and NAC strategies are $y$ and $1-y$, respectively.

\subsection{Construction of Replicator Dynamic Equations}

3.1.1. Scenario without Participation of the General Public.
The expected payoffs of the private investor under the PHS and PLS strategies are denoted by $U_{11}$ and $U_{12}$, respectively.

$$
\begin{aligned}
& U_{11}=y\left(R_{1}-C\right)+(1-y)\left(R_{2}-C\right)=y\left(R_{1}-R_{2}\right)+R_{2}-C, \\
& U_{12}=y R_{3}+(1-y) R_{4}=y\left(R_{3}-R_{4}\right)+R_{4} .
\end{aligned}
$$

The expected payoffs of the government under the AC and NAC strategies are denoted as $U_{21}$ and $U_{22}$, respectively.

$$
\begin{aligned}
& U_{21}=x G_{1}+(1-x) G_{3}=x\left(G_{1}-G_{3}\right)+G_{3}, \\
& U_{22}=x G_{2}+(1-x) G_{4}=x\left(G_{2}-G_{4}\right)+G_{4} .
\end{aligned}
$$

The replicator dynamic equations of the private investor selecting the PHS strategy and the government selecting the AC strategy are denoted as $F_{E}(x)$ and $F_{G}(y)$, respectively.

$$
\begin{aligned}
F_{E}(x) & =\frac{\mathrm{d} x}{\mathrm{~d} t}=x(1-x)\left(U_{11}-U_{12}\right) \\
& =x(1-x)\left[y\left(R_{1}-R_{2}-R_{3}+R_{4}\right)+R_{2}-R_{4}-C\right], \\
F_{G}(y) & =\frac{\mathrm{d} y}{\mathrm{~d} t}=y(1-y)\left(U_{21}-U_{22}\right) \\
& =y(1-y)\left[x\left(G_{1}-G_{2}-G_{3}+G_{4}\right)+G_{3}-G_{4}\right] .
\end{aligned}
$$

3.1.2. Scenario with Participation of the General Public. The expected payoffs of the private investor under the PHS and PLS strategies are denoted as $U P_{11}$ and $U P_{12}$, respectively.

$$
\begin{aligned}
& U P_{11}=y\left(R_{1}-R_{2}\right)(1+\lambda)+\left(R_{2}-C\right)(1+\lambda), \\
& U P_{12}=y\left(R_{3}-R_{4}\right)(1-\lambda)+R_{4}(1-\lambda) .
\end{aligned}
$$

The expected payoffs of the government under the AC and NAC strategies are denoted as $U P_{21}$ and $U P_{22}$, respectively.

$$
\begin{aligned}
& U P_{21}=x\left(G_{1}-G_{3}\right)(1+\lambda)+G_{3}(1+\lambda), \\
& U P_{22}=x\left(G_{2}-G_{4}\right)(1-\lambda)+G_{4}(1-\lambda) .
\end{aligned}
$$

The replicator dynamic equations of the private investor selecting the PHS strategy and the government selecting the AC strategy are denoted as $F P_{E}(x)$ and $F P_{G}(y)$, respectively.

$$
\begin{aligned}
F P_{E}(x) & =\frac{\mathrm{d} x}{\mathrm{~d} t}=x(1-x)\left(U P_{11}-U P_{12}\right), \\
& =x(1-x)\left\{y\left[R_{1}-R_{2}-R_{3}+R_{4}+\lambda\left(R_{1}-R_{2}+R_{3}-R_{4}\right)\right]+R_{2}-R_{4}-C+\lambda\left(R_{2}+R_{4}-C\right)\right\}, \\
F P_{G}(y) & =\frac{\mathrm{d} y}{\mathrm{~d} t}=y(1-y)\left(U P_{21}-U P_{22}\right), \\
& =y(1-y)\left\{x\left[\left(G_{1}-G_{2}-G_{3}+G_{4}\right)+\lambda\left(G_{1}+G_{2}-G_{3}-G_{4}\right)\right]+G_{3}-G_{4}+\lambda\left(G_{3}+G_{4}\right)\right\} .
\end{aligned}
$$




\subsection{Stability Analysis of Equilibriums}

3.2.1. Scenario without Participation of the General Public. According to the dynamic relationships of strategic adjustment between the government and the private investor, $F_{E}(x)$ and $F_{G}(y), F_{E}(x)=0$ and $F_{G}(y)=0$ must hold when the game between the two parties reaches an evolutionary stable state, and as a consequence, five equilibriums of the evolutionary game are obtained: $O(0,0), A(0,1), B(1,0), C(1,1), D\left(x_{0}^{*}, y_{0}^{*}\right)$, where

$$
\begin{aligned}
& x_{0}^{*}=\frac{G_{4}-G_{3}}{G_{1}-G_{2}-G_{3}+G_{4}}, \\
& y_{0}^{*}=\frac{R_{4}-R_{2}+C}{R_{1}-R_{2}-R_{3}+R_{4}} .
\end{aligned}
$$

If and only if $0 \leq x_{0}^{*} \leq 1$ and $0 \leq y_{0}^{*} \leq 1, D\left(x_{0}^{*}, y_{0}^{*}\right)$ exists and is a saddle point.

According to the stability theory of differential equations, any one of the abovementioned five equilibrium points is an evolutionary stable strategy (ESS) when it passes the stability test [34], which requires that the determinant of the Jacobian matrix $J_{0}$ satisfies the condition det $J_{0}>0$ and the trace of $J_{0}$ satisfies the condition $\operatorname{tr} J_{0}<0$. Furthermore,

$$
\begin{aligned}
J_{0} & =\left[\begin{array}{ll}
\frac{\partial F_{E}(x)}{\partial x} & \frac{\partial F_{E}(x)}{\partial y} \\
\frac{\partial F_{G}(y)}{\partial x} & \left.\frac{\partial F_{G}(y)}{\partial y}\right]
\end{array}\right], \\
\frac{\partial F_{E}(x)}{\partial x} & =(1-2 x)\left[y\left(R_{1}-R_{2}-R_{3}+R_{4}\right)+R_{2}-R_{4}-C\right], \\
\frac{\partial F_{E}(x)}{\partial y} & =x(1-x)\left(R_{1}-R_{2}-R_{3}+R_{4}\right), \\
\frac{\partial F_{G}(y)}{\partial x} & =y(1-y)\left(G_{1}-G_{2}-G_{3}+G_{4}\right), \\
\frac{\partial F_{G}(y)}{\partial y} & =(1-2 y)\left[x\left(G_{1}-G_{2}-G_{3}+G_{4}\right)+G_{3}-G_{4}\right], \\
\operatorname{det} J_{0} & =\frac{\partial F_{E}(x)}{\partial x} \cdot \frac{\partial F_{G}(y)}{\partial y}-\frac{\partial F_{E}(x)}{\partial y} \cdot \frac{\partial F_{G}(y)}{\partial x}, \\
\operatorname{tr} J_{0} & =\frac{\partial F_{E}(x)}{\partial x}+\frac{\partial F_{G}(y)}{\partial y} .
\end{aligned}
$$

On the basis of the abovementioned analysis, the following conclusions are proposed:

(i) det $\left.J_{0}\right|_{(0,0)}=\left(R_{2}-R_{4}-C\right)\left(G_{3}-G_{4}\right) \quad$ and $\left.\operatorname{tr} J_{0}\right|_{(0,0)}=\left(R_{2}-R_{4}-C\right)+\left(G_{3}-G_{4}\right)$

The point $O(0,0)$ is an ESS when $R_{2}-R_{4}-C<0$ and $G_{3}-G_{4}<0$, which indicates that the ESS between the two parties in the game is (PLS, NAC) under the conditions $R_{2}-R_{4}<C$ and $G_{3}<G_{4}$

(ii) det $\left.J_{0}\right|_{(0,1)}=\left(R_{1}-R_{3}-C\right)\left[-\left(G_{3}-G_{4}\right)\right] \quad$ and $\left.\operatorname{tr} J_{0}\right|_{(0,1)}=\left(R_{1}-R_{3}-C\right)-\left(G_{3}-G_{4}\right)$

The point $A(0,1)$ is an ESS, which means that the ESS between the two parties in the game is (PLS, AC) when $R_{1}-R_{3}<C$ and $G_{3}>G_{4}$

(iii) det $\left.J_{0}\right|_{(1,0)}=\left[-\left(R_{2}-R_{4}-C\right)\right]\left(G_{1}-G_{2}\right) \quad$ and $\left.\operatorname{tr} J_{0}\right|_{(1,0)}=-\left(R_{2}-R_{4}-C\right)+\left(G_{1}-G_{2}\right)$

The point $B(1,0)$ is an ESS, which indicates that the ESS between the two parties in the game is (PHS, NAC) when $R_{2}-R_{4}>C$ and $G_{1}<G_{2}$

(iv) det $\left.J_{0}\right|_{(1,1)}=\left[-\left(R_{1}-R_{3}-C\right)\right]\left[-\left(G_{1}-G_{2}\right)\right] \quad$ and $\left.\operatorname{tr} J_{0}\right|_{(1,1)}=-\left(R_{1}-R_{3}-C\right)-\left(G_{1}-G_{2}\right)$

The point $C(1,1)$ is an ESS, which means that the ESS between the two parties in the game is (PHS, AC) when $R_{1}-R_{3}>C$ and $G_{1}>G_{2}$

3.2.2. Scenario with Participation of the General Public. According to the dynamic relationships of strategic adjustment between the government and the private investor, $F P_{E}(x)$ and $F P_{G}(y), F P_{E}(x)=0$ and $F P_{G}(y)=0$ must hold when the game between the two parties comes to an evolutionary stable state. Consequently, five equilibriums in the evolutionary game are obtained: $O(0,0), A(0,1), B(1,0)$, $C(1,1), E\left(x_{1}^{*}, y_{1}^{*}\right)$, where

$$
\begin{aligned}
& x_{1}^{*}=\frac{G_{4}-G_{3}-\lambda\left(G_{4}+G_{3}\right)}{G_{1}-G_{2}-G_{3}+G_{4}+\lambda\left(G_{1}+G_{2}-G_{3}-G_{4}\right)}, \\
& y_{1}^{*}=\frac{R_{4}-R_{2}+C-\lambda\left(R_{4}+R_{2}-C\right)}{R_{1}-R_{2}-R_{3}+R_{4}++\lambda\left(R_{1}-R_{2}+R_{3}-R_{4}\right)} .
\end{aligned}
$$

If and only if $0 \leq x_{1}^{*} \leq 1$ and $0 \leq y_{1}^{*} \leq 1, E\left(x_{1}^{*}, y_{1}^{*}\right)$ exists and is a saddle point.

$$
\begin{aligned}
& J_{1}=\left[\begin{array}{cc}
\frac{\partial F P_{E}(x)}{\partial x} & \frac{\partial F P_{E}(x)}{\partial y} \\
\frac{\partial F P_{G}(y)}{\partial x} & \frac{\partial F P_{G}(y)}{\partial y}
\end{array}\right], \\
& \frac{\partial F P_{E}(x)}{\partial x}=(1-2 x)\left\{y\left[R_{1}-R_{2}-R_{3}+R_{4}+\lambda\left(R_{1}-R_{2}+R_{3}-R_{4}\right)\right]+R_{2}-R_{4}-C+\lambda\left(R_{2}+R_{4}-C\right)\right\},
\end{aligned}
$$




$$
\begin{aligned}
\frac{\partial F P_{G}(y)}{\partial y} & =(1-2 y)\left\{x\left[\left(G_{1}-G_{2}-G_{3}+G_{4}\right)+\lambda\left(G_{1}+G_{2}-G_{3}-G_{4}\right)\right]+G_{3}-G_{4}+\lambda\left(G_{3}+G_{4}\right)\right\} \\
\operatorname{det} J_{1} & =\frac{\partial F P_{E}(x)}{\partial x} \cdot \frac{\partial F P_{G}(y)}{\partial y}-\frac{\partial F P_{E}(x)}{\partial y} \cdot \frac{\partial F P_{G}(y)}{\partial x} \\
\operatorname{tr} J_{1} & =\frac{\partial F P_{E}(x)}{\partial x}+\frac{\partial F P_{G}(y)}{\partial y}
\end{aligned}
$$

On the basis of the abovementioned analysis, the following conclusions are proposed:

(i) $\left.\operatorname{det} J_{1}\right|_{(0,0)}=\left[R_{2}-R_{4}-C+\lambda\left(R_{2}+R_{4}-C\right)\right]\left[G_{3}-\right.$ $\left.G_{4}+\lambda\left(G_{3}+G_{4}\right)\right]$

The point $O(0,0)$ is still an ESS when $R_{2}-R_{4}-C+$ $\lambda\left(R_{2}+R_{4}-C\right)<0$ and $G_{3}-G_{4}+\lambda\left(G_{3}+G_{4}\right)<0$. If we combine the condition of $0 \leq \lambda \leq 1$ and the equilibrium conditions of the evolutionary game in (I-i), i.e., $R_{2}-R_{4}<C$ and $G_{3}<G_{4}$, we then determine that $0 \leq \lambda<\min \left\{\left(R_{4}-\left(\begin{array}{ll}R & 2\end{array}-C\right)\right) /\left(R_{4}+\right.\right.$ $\left.\left.\left(R_{2}-C\right)\right),\left(G_{4}-G_{3}\right) /\left(G_{4}+G_{3}\right)\right\}$. That is, when the ESS between the private investor and the government is (PLS, NAC) and the degree of the participation concerning the general public, namely, $\lambda$, is under the condition of $0 \leq \lambda<\min \left\{\left(R_{4}-\left(R_{2}-\right.\right.\right.$ $\left.C)) /\left(R_{4}+\left(R_{2}-C\right)\right),\left(G_{4}-G_{3}\right) /\left(G_{4}+G_{3}\right)\right\}$, the participation of the general public in PPPs cannot alter the strategy options of either the private investor or the government, and thus, the public participation in the PPP is deemed ineffective.

Rather, either when $R_{2}-R_{4}-C+\lambda\left(R_{2}+\right.$ $\left.R_{4}-C\right)>0$ and $G_{3}-G_{4}+\lambda\left(G_{3}+G_{4}\right)<0$ or when $R_{2}-R_{4}-C+\lambda\left(R_{2}+R_{4}-C\right)<0$ and $G_{3}-G_{4}+$ $\lambda\left(G_{3}+G_{4}\right)>0$, i.e., when $\left(R_{4}-\left(R_{2}-C\right)\right) /\left(R_{4}+\right.$ $\left.\left(R_{2}-C\right)\right)<\lambda<\left(G_{4}-G_{3}\right) /\left(G_{4}+G_{3}\right)$ or $\left(G_{4}-G_{3}\right) /$ $\left(G_{4}+G_{3}\right)<\lambda<\left(R_{4}-\left(R_{2}-C\right)\right) /\left(R_{4}+\left(R_{2}-C\right)\right)$,

$\operatorname{det} J_{1}<0$ and $\operatorname{tr} J_{1}$ have both positive and negative values. Thus, $O(0,0)$ is a saddle point. When $R_{2}-$ $R_{4}-C+\lambda\left(R_{2}+R_{4}-C\right)>0$ and $G_{3}-G_{4}+\lambda\left(G_{3}+\right.$ $\left.G_{4}\right)>0$, i.e., when $\max \left\{\left(R_{4}-\left(R_{2}-C\right)\right) /\left(R_{4}+\right.\right.$ $\left.\left.\left(R_{2}-C\right)\right),\left(G_{4}-G_{3}\right) /\left(G_{4}+G_{3}\right)\right\}<\lambda \leq 1$, det $J_{1}>0$ and $\operatorname{tr} J_{1}>0$. Thus, $O(0,0)$ is an unstable point. Accordingly, the abovementioned substantiate that when the ESS between the private investor and the government is (PLS, NAC) and the degree of public participation $\lambda$ is under the condition of $\min \left\{\left(R_{4}-\left(R_{2}-C\right)\right) /\left(R_{4}+\left(R_{2}-C\right)\right),\left(G_{4}-G_{3}\right) /\right.$ $\left.\left(G_{4}+G_{3}\right)\right\}<\lambda \leq 1$, participation of the general public in PPPs is effective and is able to play a substantive role in adjusting the equilibrium strategies between the government and the private investor.

(ii) $\left.\operatorname{det} J_{1}\right|_{(0,1)}=\left[R_{1}-R_{3}-C+\lambda\left(R_{1}+R_{3}-C\right)\right]\left\{-\left[G_{3}-\right.\right.$ $\left.\left.G_{4}+\lambda\left(G_{3}+G_{4}\right)\right]\right\}$

The point $A(0,1)$ is still an ESS when $R_{1}-R_{3}-C+$ $\lambda\left(R_{1}+R_{3}-C\right)<0$ and $G_{3}-G_{4}+\lambda\left(G_{3}+G_{4}\right)>0$. When we combine the condition of $0 \leq \lambda \leq 1$ and the equilibrium conditions of the evolutionary game in (I-ii), i.e., $R_{1}-R_{3}<C$ and $G_{3}>G_{4}$, we then determine that $0 \leq \lambda<\left(R_{3}-\left(R_{1}-C\right)\right) /\left(R_{3}+\left(R_{1}-C\right)\right)$. That is, when the ESS between the private investor and the government is (PLS, AC) and the degree of public participation $\lambda$ is under the condition of $0 \leq \lambda<\left(R_{3}-\left(R_{1}-C\right)\right) / R_{3}+\left(R_{1}-C\right)$, public participation in PPPs cannot alter the strategy options of the government or the private investor and is, therefore, deemed ineffective.

When $R_{1}-R_{3}-C+\lambda\left(R_{1}+R_{3}-C\right)<0$ and $G_{3}-$ $G_{4}+\lambda\left(G_{3}+G_{4}\right)<0$ or when $R_{1}-R_{3}-C+\lambda\left(R_{1}+\right.$ $\left.R_{3}-C\right)>0$ and $G_{3}-G_{4}+\lambda\left(G_{3}+G_{4}\right)>0$, that is, when $\left(R_{3}-\left(R_{1}-C\right)\right) /\left(R_{3}+\left(R_{1}-C\right)\right)<\lambda \leq 1, A(0$, $1)$ is a saddle point. When $R_{1}-R_{3}-C+\lambda\left(R_{1}+\right.$ $\left.R_{3}-C\right)>0$ and $G_{3}-G_{4}+\lambda\left(G_{3}+G_{4}\right)<0$, that is, when $\lambda \in \phi, A(0,1)$ is an unstable point. According to these results, when the ESS between the private investor and the government is (PLS, AC) and the degree of public participation $\lambda$ is under the condition where $\left(R_{3}-\left(R_{1}-C\right)\right) /\left(R_{3}+\left(R_{1}-C\right)\right)$ $<\lambda \leq 1$, public participation in PPPs is effective and plays a substantive role in adjusting the equilibrium of the strategies between the two parties.

(iii) $\left.\operatorname{det} J_{1}\right|_{(1,0)}=$ $\left\{-\left[R_{2}-R_{4}-C+\lambda\left(R_{2}+R_{4}-C\right)\right]\right\}\left[G_{1}-G_{2}+\lambda\left(G_{1}+\right.\right.$ $\left.\left.G_{2}\right)\right]$

The point $B(1,0)$ is still an ESS when $R_{2}-R_{4}-C+$ $\lambda\left(R_{2}+R_{4}-C\right)>0$ and $G_{1}-G_{2}+\lambda\left(G_{1}+G_{2}\right)<0$. When we combine the condition where $0 \leq \lambda \leq 1$ and the equilibrium conditions of the evolutionary game in (I-iii), i.e., $R_{2}-R_{4}>C$ and $G_{1}<G_{2}$, we then determine that $0 \leq \lambda<\left(G_{2}-G_{1}\right) /\left(G_{2}+G_{1}\right)$. That is, when the ESS between the private investor and the government is (PHS, NAC) and the degree of public participation $\lambda$ meets the condition where $0 \leq \lambda<\left(G_{2}-G_{1}\right) / G_{2}+G_{1}$, public participation in PPPs cannot alter the strategy options of the two parties and, therefore, is deemed ineffective.

Rather, when $R_{2}-R_{4}-C+\lambda\left(R_{2}+R_{4}-C\right)>0$ and $G_{1}-G_{2}+\lambda\left(G_{1}+G_{2}\right)>0$ or when $R_{2}-R_{4}-C+$ $\lambda\left(R_{2}+R_{4}-C\right)<0$ and $G_{1}-G_{2}+\lambda\left(G_{1}+G_{2}\right)<0$, that is, when $\left(G_{2}-G_{1}\right) /\left(G_{2}+G_{1}\right)<\lambda \leq 1, B(1,0)$ is the saddle point. When $R_{2}-R_{4}-C+\lambda\left(R_{2}+R_{4}-\right.$ $C)<0$ and $G_{1}-G_{2}+\lambda\left(G_{1}+G_{2}\right)>0$, that is, when $\lambda \in \phi, B(1,0)$ is an unstable point. These calculations indicate that when the ESS between the private investor and the government is (PHS, NAC) and the 
TABLE 1: Game payoff matrices in PPPs.

\begin{tabular}{lccccc}
\hline \multicolumn{2}{c}{ Scenario I: without participation of the general public } & \multicolumn{2}{c}{ Scenario II: with participation of the general public } \\
\hline \multirow{2}{*}{ Private investor } & GC $(y)$ & Government & Private investor $(1-y)$ & AC $(y)$ & Government \\
& $R_{1}-C$ & $R_{2}-C$ & PHS $(x)$ & $\left(R_{1}-C\right)(1+\lambda)$ & $\left(R_{2}-C\right)(1+\lambda)$ \\
\multirow{2}{*}{ PHS $(x)$} & $G_{1}$ & $G_{2}$ & \multirow{2}{*}{ PLS $(1-x)$} & $G_{1}(1+\lambda)$ & $R_{3}(1-\lambda)$ \\
\hline \multirow{2}{*}{ PLS $(1-x)$} & $R_{3}$ & $R_{4}$ & $G_{3}(1+\lambda)$ & $R_{4}(1-\lambda)$ \\
& $G_{3}$ & $G_{4}$ & & $G_{4}(1-\lambda)$ \\
\hline
\end{tabular}

TABLE 2: Results of the evolutionary game in PPPs with public participation.

\begin{tabular}{|c|c|c|c|}
\hline & Conditions & $\begin{array}{l}\text { Initial evolutionary stability strategies } \\
\text { of the government and the private } \\
\text { sector }\end{array}$ & Ineffective degree of public participation \\
\hline Situation 1 & $\begin{array}{c}R_{2}-R_{4}<C \\
G_{3}<G_{4}\end{array}$ & $\begin{array}{c}\text { Not actively cooperating } \\
\text { Providing low-quality public services/ } \\
\text { products }\end{array}$ & $0 \leq \lambda<\min \left\{\left(R_{4}-\left(R_{2}-C\right)\right) /\left(R_{4}+\left(R_{2}-C\right)\right),\left(G_{4}-G_{3}\right) /\left(G_{4}+G_{3}\right)\right\}$ \\
\hline Situation 2 & $\begin{array}{c}R_{1}-R_{3}<C \\
G_{3}>G_{4}\end{array}$ & $\begin{array}{c}\text { Actively cooperating } \\
\text { Providing low-quality public services/ } \\
\text { products }\end{array}$ & $0 \leq \lambda<\left(R_{3}-\left(R_{1}-C\right)\right) /\left(R_{3}+\left(R_{1}-C\right)\right)$ \\
\hline Situation 3 & $\begin{array}{c}R_{2}-R_{4}>C \\
G_{1}<G_{2}\end{array}$ & $\begin{array}{c}\text { Not actively cooperating } \\
\text { Providing high-quality public services/ } \\
\text { products }\end{array}$ & $0 \leq \lambda<\left(G_{2}-G_{1}\right) /\left(G_{2}+G_{1}\right)$ \\
\hline Situation 4 & $\begin{array}{c}R_{1}-R_{3}>C \\
G_{1}>G_{2}\end{array}$ & $\begin{array}{c}\text { Actively cooperating } \\
\text { Providing high-quality public services/ } \\
\text { products }\end{array}$ & $\lambda \in[0,1]$ \\
\hline
\end{tabular}

degree of public participation $\lambda$ meets the condition where $\left(G_{2}-G_{1}\right) /\left(G_{2}+G_{1}\right)<\lambda \leq 1$, public participation in PPPs becomes effective and plays a substantive role in adjusting the equilibrium of the strategies between the two parties.

(iv) $\left.\operatorname{det} J_{1}\right|_{(1,1)}=\left\{-\left[\begin{array}{lll}R_{1}- & R_{3}-C+\lambda\left(R_{1}+R_{3}-C\right)\end{array}\right]\{-\right.$ $\left.\left[G_{1}-G_{2}+\lambda\left(G_{1}+G_{2}\right)\right]\right\}$

The point $C(1,1)$ is still an ESS when $R_{1}-R_{3}-C+$ $\lambda\left(R_{1}+R_{3}-C\right)>0$ and $G_{1}-G_{2}+\lambda\left(G_{1}+G_{2}\right)>0$. When we combine the condition of $0 \leq \lambda \leq 1$ and the equilibrium conditions of the evolutionary game in (Iiv), i.e., $R_{1}-R_{3}>C$ and $G_{1}>G_{2}$, we then determine that $\lambda \in[0,1]$. That is, when the ESS between the private investor and the government is (PHS, AC), no degree of public participation can change the status of cooperation between the two parties. It further indicates that although public participation in PPPs is ineffective in this context, it is due to the original efforts of public-private collaborations.

The abovementioned analysis on the results concerning the evolutionary game of the government and the private investor in PPPs with participation of the general public is summarized in Table 2.

\section{Numerical Analysis}

4.1. Simulation of the Evolutionary Process. To visually verify the previous analysis, MATLAB R2017b was used to simulate the dynamic evolutionary process. Because it is difficult to obtain the actual data in an all-round way, this paper makes a reasonable assumption of the parameters in the context of the existing cases in China.

Based on the qualifications in situation 1 and as presented in Table 2, the initial value of each parameter is set as $R_{1}=150, R_{2}=140, R_{3}=90, R_{4}=80, C=70, G_{1}=7, G_{2}=6$, $G_{3}=3$, and $G_{4}=4, \lambda=0.05$. As presented in Figures 3(a) and $3(\mathrm{~b}), O(0,0)$ is the ESS of both the evolutionary games between the government and the private investor without and with participation of the general public under different initial conditions, which is consistent with the conclusions of the evolutionary game model.

Based on the requirements in situation 2, the initial value of each parameter is set as $R_{1}=150, R_{2}=140, R_{3}=90, R_{4}=80$, $C=70, G_{1}=7, G_{2}=6, G_{3}=4, G_{4}=3$, and $\lambda=0.05$. As presented in Figures $4(\mathrm{a})$ and $4(\mathrm{~b}), A(0,1)$ is the ESS of both the evolutionary games without and with participation of the general public under different initial conditions, which is consistent with the conclusions of the evolutionary game model.

Based on the qualifications in situation 3, the initial value of each parameter is set as $R_{1}=150, R_{2}=140, R_{3}=90, R_{4}=70$, $C=60, G_{1}=6, G_{2}=7, G_{3}=4, G_{4}=3$, and $\lambda=0.05$. As evidenced in Figures 5(a) and 5(b), B(1,0) is the ESS of both the evolutionary games without and with participation of the general public under different initial conditions, which is consistent with the conclusions of the evolutionary game model.

Based on the stipulations in situation 4 , the initial value of each parameter is set as $R_{1}=170, R_{2}=140, R_{3}=90, R_{4}=80$, 


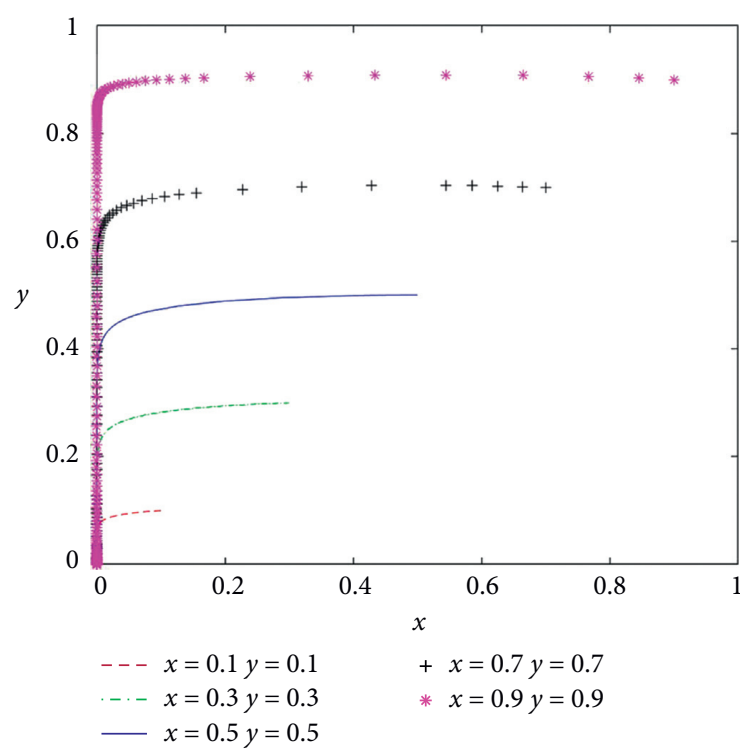

(a)

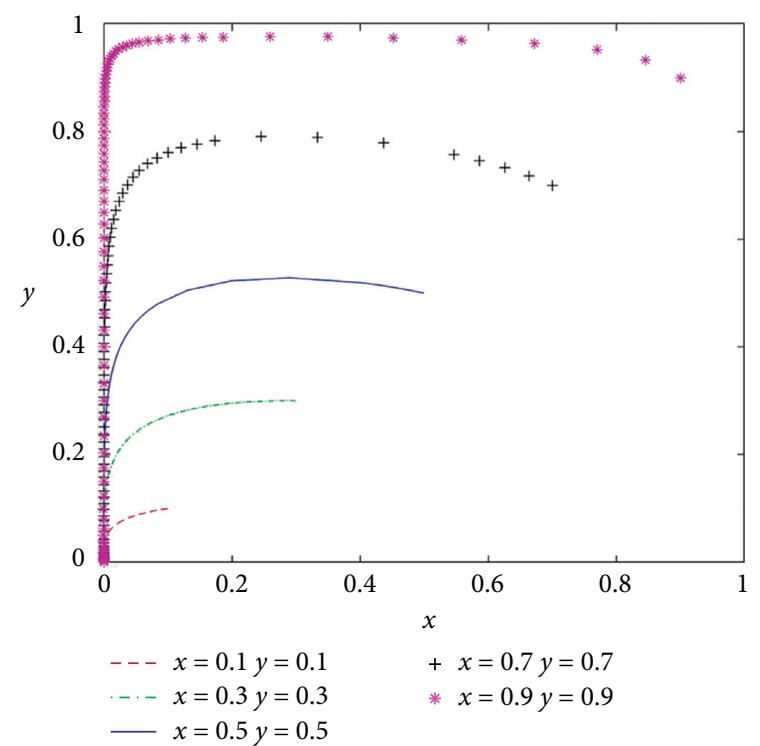

(b)

Figure 3: The evolutionary trajectories of players in situation 1. (a) Scenario without public participation. (b) Scenario with public participation.

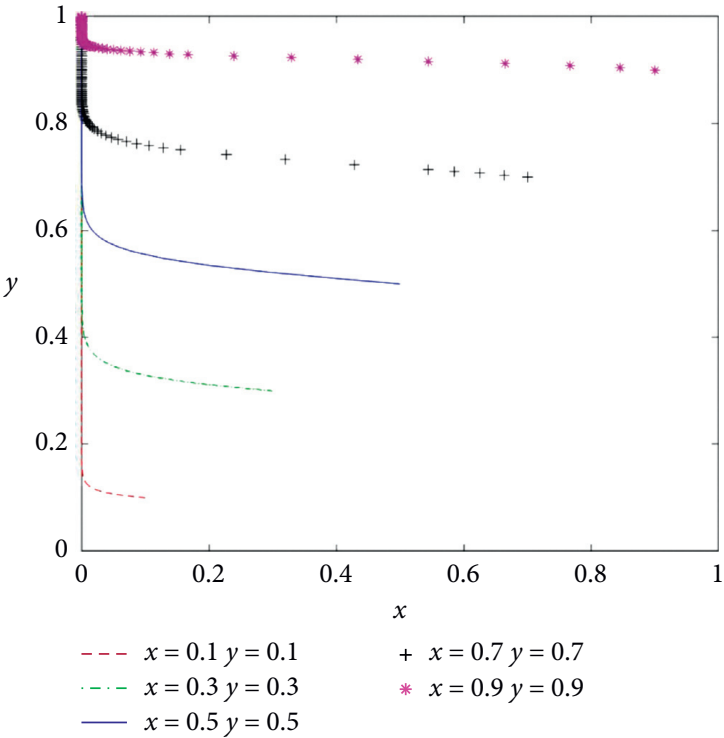

(a)

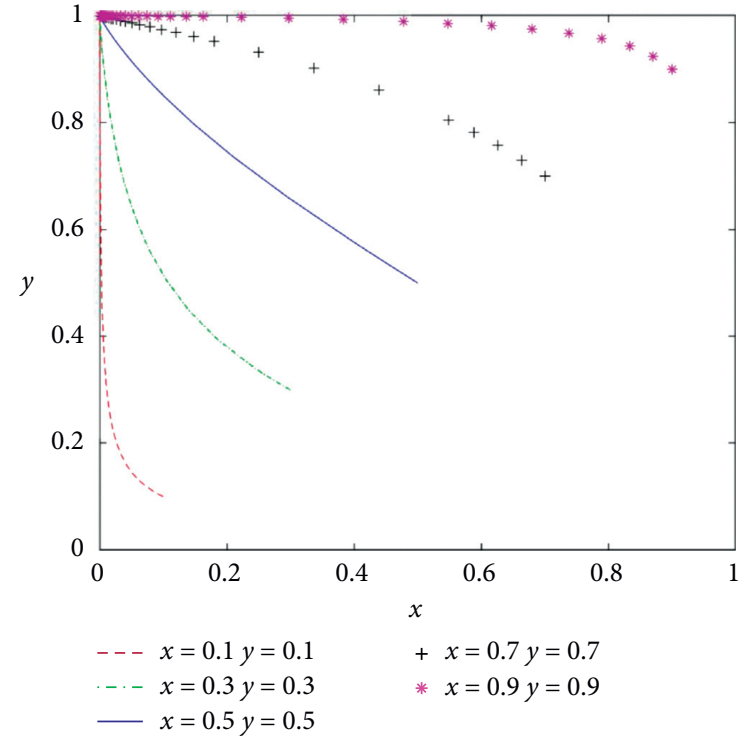

(b)

Figure 4: The evolutionary trajectories of players in situation 2. (a) Scenario without public participation. (b) Scenario with public participation.

$C=70, G_{1}=7, G_{2}=6, G_{3}=4$, and $G_{4}=3$. Referencing Figures $6(\mathrm{a})-6(\mathrm{c}), C(1,1)$ is the ESS of the evolutionary games without and with participation of the general public under different initial conditions, which is consistent with the conclusions of the evolutionary game model.

4.2. Influence of Public Participation. The impact of public participation on the evolutionary game between the government and the private investor in PPPs is examined. The parameters remain the same as those in the abovementioned simulations. In situation 1 , the degree of public participation $\lambda$ changes, and the evolutionary results are presented in Figure 7(a). As evidenced in Figure 7(a), an increase in $\lambda$ results in the evolutionary trajectories moving from $O(0,0)$ to $C(1,1)$. When the degree of public participation is low $(\lambda<\min \{0.067$, $0.143\})$, the evolutionary trajectories reach ESS $(0,0)$, which means $\lambda$ falls within the interval of ineffective public 


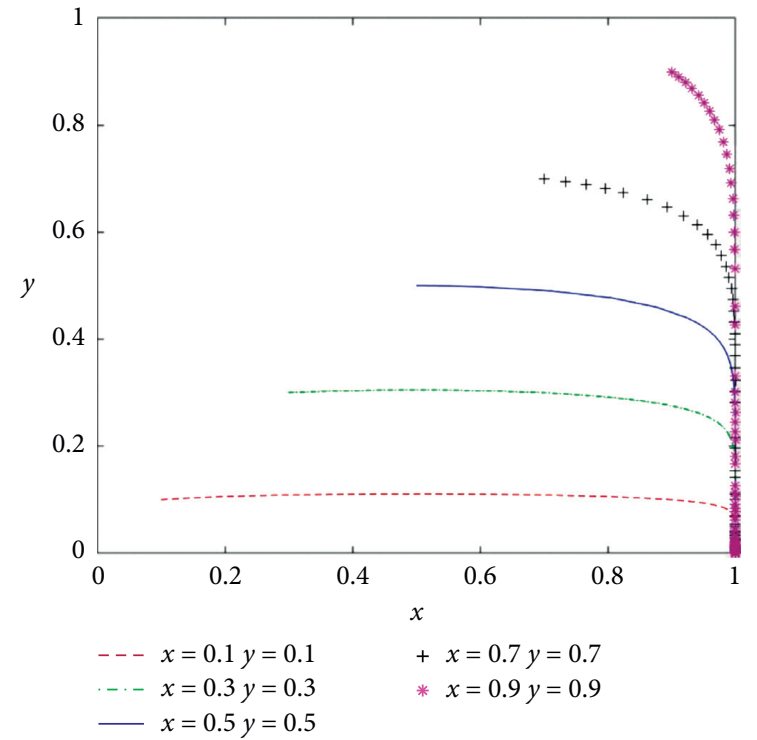

(a)

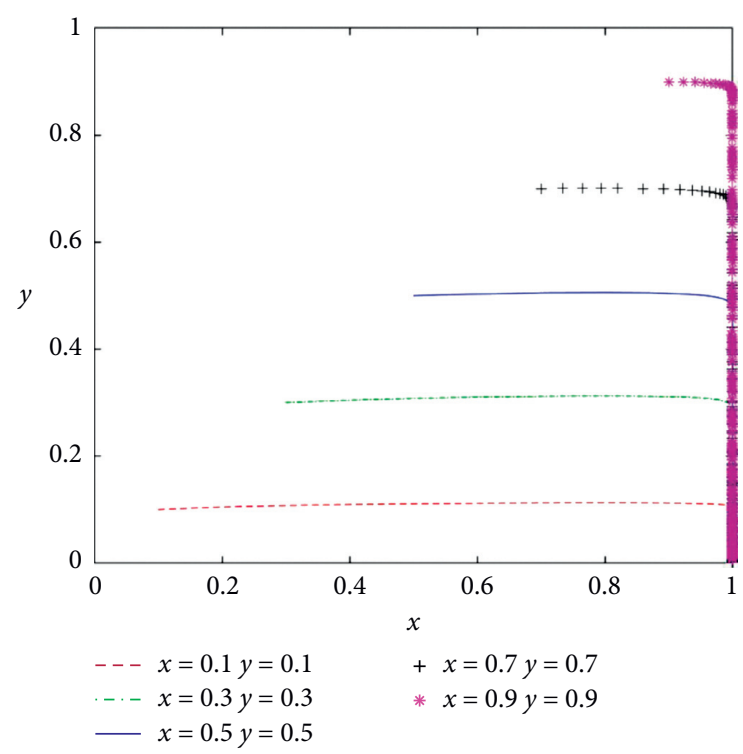

(b)

FIGURE 5: The evolutionary trajectories of players in situation 3. (a) Scenario without public participation. (b) Scenario with public participation.

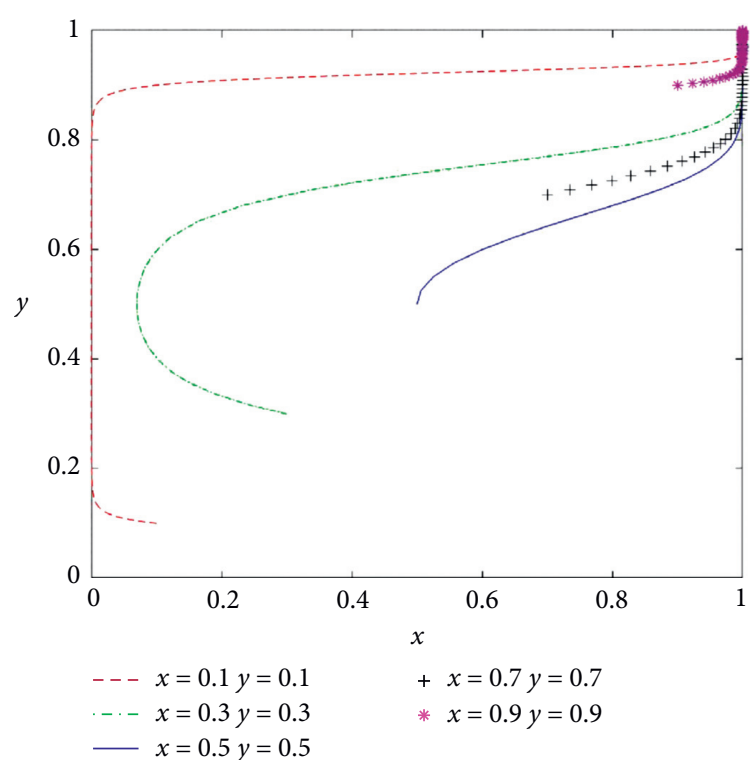

(a)

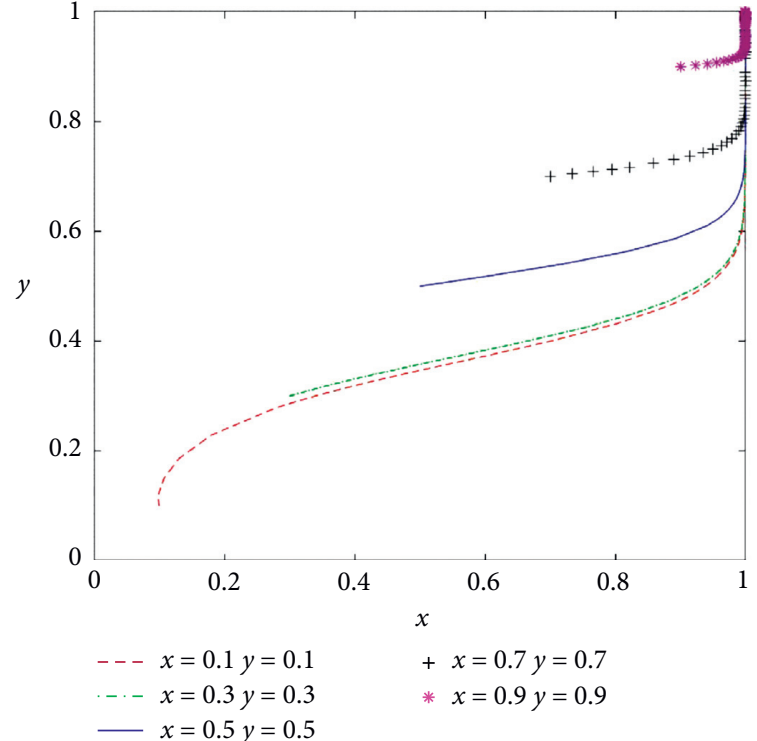

(b)

Figure 6: Continued. 


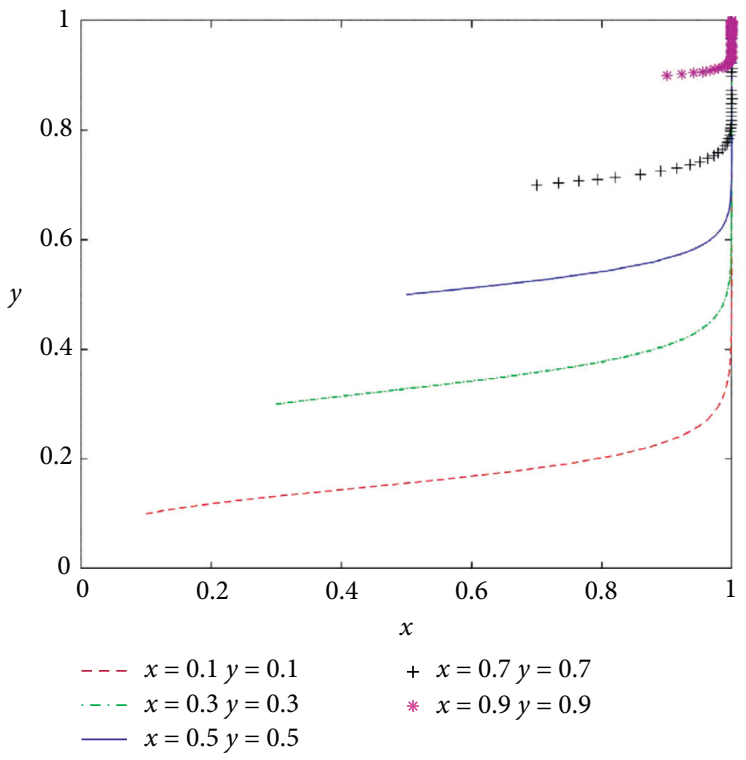

(c)

FIGURE 6: The evolutionary trajectories of players in situation 4. (a) Without public participation. (b) With public participation and $\lambda=0.05$. (c) With public participation and $\lambda=0.1$.

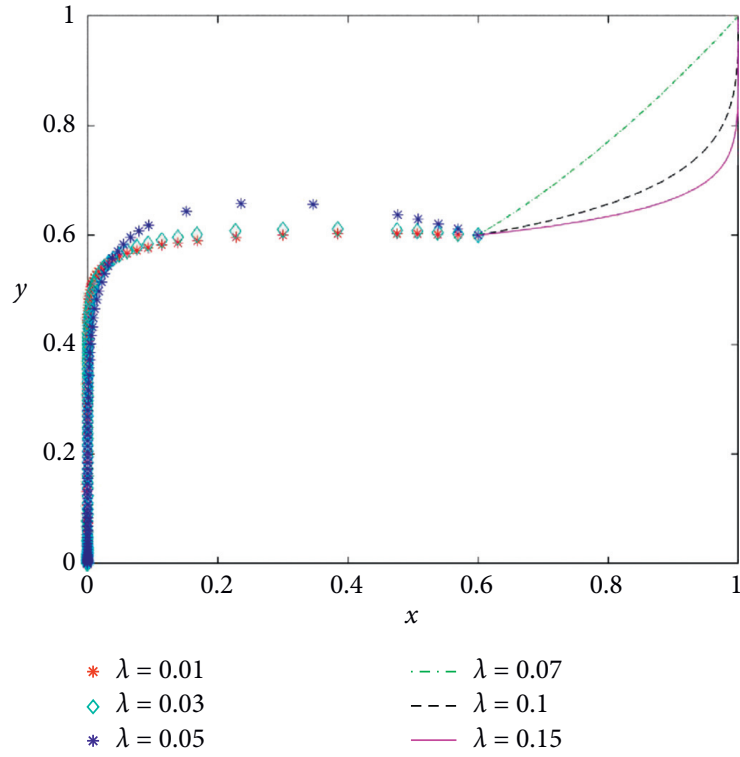

(a)

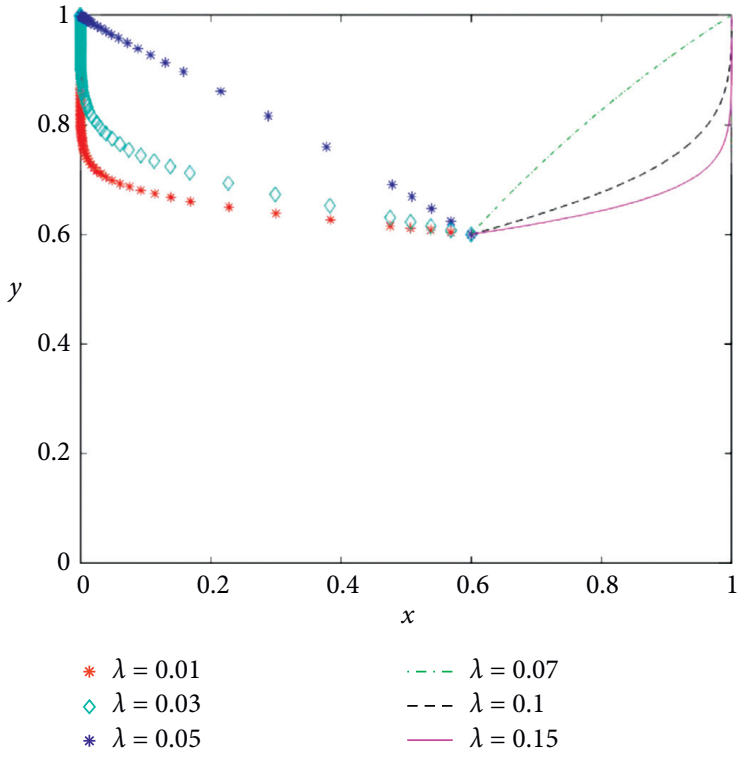

(b)

Figure 7: Continued. 


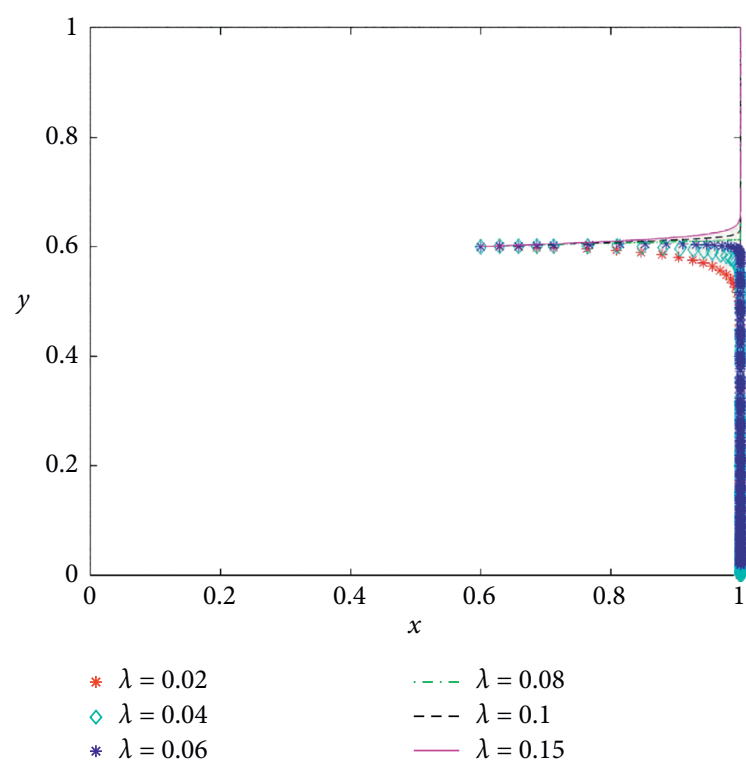

(c)

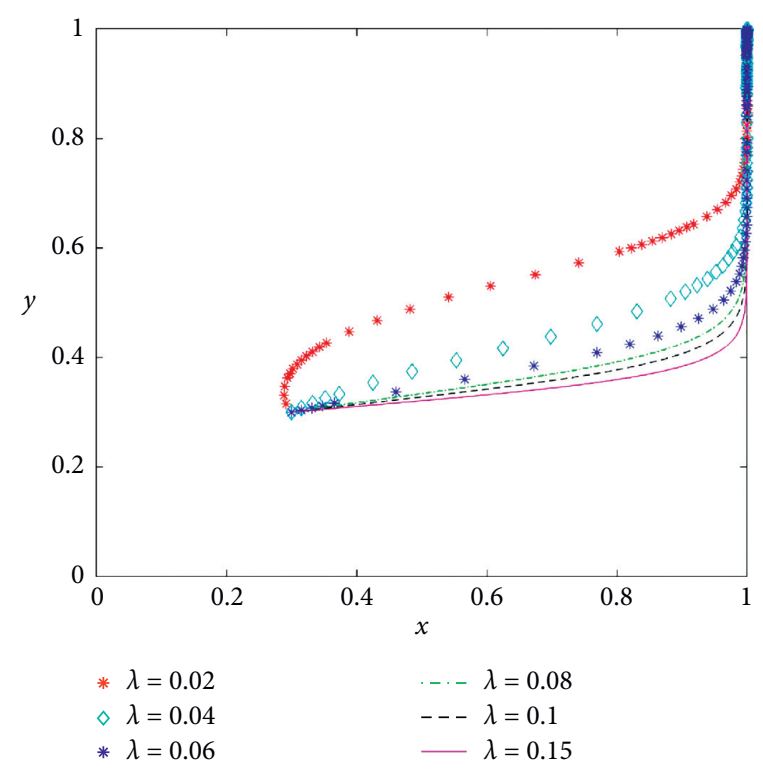

(d)

Figure 7: The evolutionary trajectories of players when the degree of public participation changes. (a) Situation 1. (b) Situation 2. (c) Situation 3. (d) Situation 4.

participation, as in situation 1, where the strategies of the government and the private investor remain the same as in the situation where there is no public participation, a finding that is consistent with the conclusions of the evolutionary game model. When the degree of public participation is high $(\lambda \geq \min \{0.067,0.143\})$ and out of the range of ineffective public participation, the evolutionary trajectories reach ESS (1, 1), which means that public participation in the two-party game is effective and that it not only affects the strategic behaviors of the two parties but also causes the cooperation between the two parties to develop in a positive direction.

Similarly, with the increase of $\lambda$, the evolutionary trajectories evolve from $A(0,1)$ to $C(1,1)$ in situation 2 , as presented in Figure $7(\mathrm{~b})$; the boundary value of $\lambda$ is 0.059 , transitioning from $B(1,0)$ to $C(1,1)$ in situation 3 , as presented in Figure 7(c); and the boundary value of $\lambda$ is 0.077 with the evolutionary trajectories always reaching $C(1,1)$ in situation 4 , regardless of the initial values of $\lambda$, as presented in Figure $7(\mathrm{~d})$.

\section{Conclusions and Suggestions}

5.1. Discussion and Practical Implications of the Evolutionary Game. In this paper, we focus on the appropriate public participation to promote the collaborations between the government and the private investor in PPPs. Based on the evolutionary game theory, the boundary conditions and the effective thresholds of public participation in the two-party evolutionary game are proposed. The potential impacts of public participation on PPPs can be explained as follows.

First, public participation in PPP projects is different from public participation in general commercial projects or government investment projects. The particularity of public participation in PPPs is that it is able to modify the partnerships between the government and the private investor. As the analysis of the model and the data simulation indicate, even though the initial status of the cooperative strategies between the two parties may be (NAC, PLS), (AC, PLS), or (NAC, PHS), they are transformed into (AC, PHS) strategies after the introduction of a certain participation of the general public.

As a main stakeholder, the general public has the right and the responsibility participate in the development of PPP projects. However, allowing the general public to participate in the decision-making process of PPPs inevitably leads to the reconstruction of the benefit structure and institutional mechanism. The essence of public participation in PPPs is that the general public restricts the decision-making powers of both the government and the private investor due to their right to participate, thus resulting in the sharing of the decision-making powers of the two parties. It must be clarified that this does not mean that the general public replaces the relevant government or the private investor in making decisions for the PPP projects, as the two participants retain the ultimate right to make decisions. Therefore, public participation in PPP projects forms trilateral cooperative interactions between the government and the general public, the private investor and the general public, and the government and the private investor. Public participation could protect public interest and promote the evolution of the strategy behaviors from negative collaboration to positive collaboration in both the government and the private investor, as evidenced in Figure 7. In addition, public participation in PPPs does not result in the deterioration of the state of the original positive collaboration in the two parties such as in situation 4.

Second, public participation in PPPs is not always effective. The analysis of ESS in the evolutionary game model reveals that when the government and the private investor 
are in a certain initial equilibrium state and participation of the general public is in a certain degree, as listed in Table 2, the equilibrium strategies of both parties cannot be modified, as presented in Figures 3-6.

It is necessary to pay attention not only to whether the general public have been involved in PPP projects but also to whether the public involvement is effective. There is a difference between nominal and substantive participation. In practice, public participation in some projects is only the former one. For example, the general public may be introduced in PPPs and allowed to express their views, but no follow-up steps are involved. This is merely a waste of human, material, and financial resources, and no more effect is produced, whereas effective and substantive participation of the general public is needed for PPPs, and it should be able to regulate the cooperation behaviors between the government and the private investor, balance the needs of the stakeholders, and promote the sustainable development of PPP projects.

Third, there are differences in the degrees of public participation in PPPs based on the existing conditions. According to the results of the evolutionary game between the government and the private investor, when the two parties are in different initial equilibriums, such as (NAC, PLS) or (AC, PLS) or (NAC, PHS) or (AC, PHS), the boundary conditions for participation of the general public, which effectively play an important role in regulating the evolutionary behaviors of both parties, are various and depend on the different variables. Thus, the degree of public participation in PPPs is not fixed but is rather measured by corresponding intervals according to the specific states of two-party cooperation, as presented in Table 2 and Figure 7. Only with such degrees of public participation can the government change its strategic choice from NAC to AC and the private investor change its strategic choice from PLS to PHS. In this way, participation of the general public in PPPs plays an effective role in regulating the evolution of twoparty stability.

\subsection{Recommendations regarding Public Participation in PPPs.} In view of the abovementioned analysis regarding the results of the evolutionary game, some recommendations are further proposed.

First, the activities of public participation in PPPs should be evaluated. The premise that the public participation is always effective is not beneficial. To enhance the effectiveness of public participation in PPPs, it is necessary to (a) evaluate the process of public participation from the perspective of scientificity, authenticity, and rationality, (b) focus on the whole process of public participation and emphasize the operation of each stage and detail, (c) match the arrangement of public participation in PPPs to the expected purpose and assess the effect of the arrangement, and (d) balance the costs and benefits derived from public participation among the interested parties, i.e., the government, the private investor, the general public, and the PPP project itself.

Second, it is necessary to consider the different situations and properly introduce the concept of public participation. Effective participation of the general public in PPPs is not a static or fixed state. Rather, the degree of public participation in PPPs depends on the status of collaboration between the government and the private investor and on certain variables, such as revenues and costs related to both parties. Thus, appropriate participation of the general public in PPP projects should (a) consider the objectives, types, and properties of the projects and then cautiously disclose information about the status of two-party collaborations and (b) establish reasonable themes, periods, modes, and approaches for public participation in PPPs based on the indirect effect that such participation brings to the project.

Third, the legal system related to public participation in PPPs should be improved. Public participation cannot be performed only as a statutory obligation, as doing so does not reflect the true commitment of the general public to participation or the value of public participation in PPPs. At present, because legal documents have not been formed in most countries, the participation of the general public at each stage of the PPP project, i.e., decision making, design, construction, operation, and transfer, is limited, and hence, the interests and suggestions of the general public are not fully considered. Thus, it is necessary to form a relatively perfect legal system and establish policies regarding public participation in PPPs to ensure a three-way symmetrical interaction among the government, the private investor, and the general public and to make certain that the main stakeholders of the three parties have the opportunity to participate in the decision-making process of the PPPs.

Four, there must be an active environment in which public participation is valued by PPPs. On the one hand, the recognition by and positive attitude of the government and society with respect to public participation and equal communication and dialogue with the general public could promote timely public access to information regarding projects and provide the general public the opportunity to express their ideas and views. On the other hand, the nature and state of the participants are also critical to the effectiveness of public participation. Characteristics of the general public such as the identity, quantity, ability, and interest of the participants directly influence whether public participation best benefits the general public itself or the group represented by the general public and whether public participation enhances the social benefits acquired from the development of PPP projects. Hence, it is necessary to create a better environment and improve conditions for public participation from more than one dimension, e.g., the government, society, and the general public, to enhance the strength and depth of public participation in PPPs, and to enable public participation to effectively regulate and monitor the PPPs.

\section{Data Availability}

The data used to support the findings of this study are included within the article.

\section{Conflicts of Interest}

The authors declare that they have no conflicts of interest. 


\section{Acknowledgments}

This research was supported by the National Natural Science Foundation of China with Grant nos. 71802103, 71734001, and 71772082, National Key Research and Development Project with Grant no. 2019YFD1101103, Humanities and Social Science Foundation of Ministry of Education of China with Grant nos. 19YJC630068 and 16YJC630107, Liaoning Social Science Planning Fund with Grant no. L15BGL005, Foundation of Liaoning Educational Committee with Grant no. 2019LNQN13, and Foundation of University of Science and Technology Liaoning with Grant no. 2018RC09.

\section{References}

[1] C. M. Ana, C. .,M. Rui, and O. C. Carlos, "Public-private partnerships for wind power generation: the portuguese case," Energy Policy, vol. 39, pp. 94-104, 2011.

[2] R. Osei-Kyei and A. P. C. Chan, "Review of studies on the critical success factors for public-private partnership (PPP) projects from 1990 to 2013," International Journal of Project Management, vol. 33, no. 6, pp. 1335-1346, 2015.

[3] Y. Fang, W. Wei, F. Liu, S. Mei, L. Chen, and J. Li, "Improving solar power usage with electric vehicles: analyzing a publicprivate partnership cooperation scheme based on evolutionary game theory," Journal of Cleaner Production, vol. 233, pp. 1284-1297, 2019.

[4] D. Grimsey and M. Lewis, Public Private Partnership: The World-wide Revolution in Infrastructure Provision and Project Finance, Edward Elgar Publishing, Cheltenham, UK, 2004.

[5] J. Song, D. Song, X. Zhang, and Y. Sun, "Risk identification for PPP waste-to-energy incineration projects in China," Energy Policy, vol. 61, pp. 953-962, 2013.

[6] E. J. Boyer, D. M. Van Slyke, and J. D. Rogers, "An empirical examination of public involvement in public-private partnerships: qualifying the benefits of public involvement in PPPs," Journal of Public Administration Research and Theory, vol. 26, pp. 45-61, 2016.

[7] N. M. El-Gohary, H. Osman, and T. E. El-Diraby, "Stakeholder management for public private partnerships," International Journal of Project Management, vol. 24, no. 7, pp. 595-604, 2006.

[8] M. Siemiatycki, "Delivering transportation infrastructure through public-private partnerships: planning concerns," Journal of the American Planning Association, vol. 76, no. 1, pp. 43-58, 2009.

[9] W. Majamaa, S. Junnila, H. Doloi, and E. Niemostö, "Enduser oriented public-private partnerships in real estate industry," International Journal of Strategic Property Management, vol. 12, no. 1, pp. 1-17, 2008.

[10] P. D. Rwelamila, P. Fewings, and C. Henjewele, "Addressing the missing link in PPP projects: what constitutes the public?" Journal of Management in Engineering, vol. 31, Article ID 04014085, 2014.

[11] X. Shan, W. Hou, X. Ye, and C. Wu, "Decision-making criteria of PPP projects: stakeholder theoretic perspective," World Academy of Science, Engineering and Technology, vol. 5, pp. 631-635, 2011.

[12] T.-l. Lui, "City-branding without content: Hong Kong's aborted West Kowloon mega-project, 1998-2006," International Development Planning Review, vol. 30, no. 3, pp. 215226, 2008
[13] R. A. Irvin and J. Stansbury, "Citizen participation in decision making: is it worth the effort?" Public Administration Review, vol. 64, no. 1, pp. 55-65, 2004.

[14] S. T. Ng, J. M. W. Wong, and K. K. W. Wong, "A public private people partnerships ( $\mathrm{P} 4)$ process framework for infrastructure development in Hong Kong," Cities, vol. 31, pp. 370-381, 2013.

[15] N. Carbonara and R. Pellegrino, "Revenue guarantee in publicprivate partnerships: a win-win model," Construction Management and Economics, vol. 36, no. 10, pp. 584-598, 2018.

[16] L. Jin, Z. Zhang, and J. Song, "Profit allocation and subsidy mechanism for public-private partnership toll road projects," Journal of Management in Engineering, vol. 36, no. 3, Article ID 04020011, 2020.

[17] T. Liu, M. Bennon, M. J. Garvin, and S. Wang, "Sharing the big risk: assessment framework for revenue risk sharing mechanisms in transportation public-private partnerships," Journal of Construction Engineering and Management, vol. 143, no. 12, Article ID 04017086, 2017.

[18] R. Pellegrino, N. Carbonara, and N. Costantino, "Public guarantees for mitigating interest rate risk in PPP projects," Built Environment Project and Asset Management, vol. 9, no. 2, pp. 248-261, 2019.

[19] A. Fung, "Democratic theory and political science: a pragmatic method of constructive engagement," American Political Science Review, vol. 101, no. 3, pp. 443-458, 2007.

[20] L. Laurian and M. M. Shaw, "Evaluation of public participation," Journal of Planning Education and Research, vol. 28, no. 3, pp. 293-309, 2008.

[21] M. Buchy and S. Hoverman, "Understanding public participation in forest planning: a review," Forest Policy and Economics, vol. 1, no. 1, pp. 15-25, 2000.

[22] E. Mannigel, "Integrating parks and people: how does participation work in protected area management?" Society \& Natural Resources, vol. 21, no. 6, pp. 498-511, 2008.

[23] V. J. Michener, "The participatory approach: contradiction and co-option in burkina faso," World Development, vol. 26, no. 12, pp. 2105-2118, 1998.

[24] G. Rowe and L. J. Frewer, "Public participation methods: a framework for evaluation," Science, Technology, \& Human Values, vol. 25, no. 1, pp. 3-29, 2000.

[25] O. Renn, T. Webler, H. Rakel, P. Dienel, and B. Johnson, "Public participation in decision making: a three-step procedure," Policy Sciences, vol. 26, no. 3, pp. 189-214, 1993.

[26] T. Webler, S. Tuler, and R. Krueger, "What is good public participation process? five perspectives from the public," Environmental Management, vol. 27, pp. 435-450, 2001.

[27] S. R. Arnstein, "A ladder of citizen participation," Journal of the American Institute of Planners, vol. 35, no. 4, pp. 216-224, 1969.

[28] A. Booth and G. Halseth, "Why the public thinks natural resources public participation processes fail: a case study of British Columbia communities," Land Use Policy, vol. 28, no. 4, pp. 898-906, 2011.

[29] D. Kreps, Game Theory and Economic Modeling, Oxford University Press, Oxford, UK, 1990.

[30] R. Gardner, Games for Business and Economics, John Wiley \& Sons, Hoboken, NJ, USA, 1995.

[31] J. M. Smith and G. R. Price, "The logic of animal conflict," Nature, vol. 246, no. 5427, pp. 15-18, 1973.

[32] W. Chen and Z.-H. Hu, "Using evolutionary game theory to study governments and manufacturers' behavioral strategies under various carbon taxes and subsidies," Journal of Cleaner Production, vol. 201, pp. 123-141, 2018. 
[33] X. Zhang, Y. Zhou, and Q. Han, "Game theory-based environmental LCC control behavior analysis," Journal of Cleaner Production, vol. 211, pp. 1527-1533, 2019.

[34] D. Friedman, "Evolutionary games in economics," Econometrica, vol. 59, no. 3, pp. 637-666, 1991.

[35] P. W. Kennedy, "Equilibrium pollution taxes in open economies with imperfect competition," Journal of Environmental Economics and Management, vol. 27, no. 1, pp. 49-63, 1994.

[36] A. A. Moledina, J. S. Coggins, S. Polasky, and C. Costello, "Dynamic environmental policy with strategic firms: prices versus quantities," Journal of Environmental Economics and Management, vol. 45, no. 2, pp. 356-376, 2003.

[37] S. Barrett, "Strategic environmental policy and intrenational trade," Journal of Public Economics, vol. 54, no. 3, pp. 325-338, 1994.

[38] C. Liu, W. Huang, and C. Yang, "The evolutionary dynamics of China's electric vehicle industry - taxes vs. subsidies," Computers \& Industrial Engineering, vol. 113, pp. 103-122, 2017.

[39] B. Wu, P. Liu, and X. Xu, "An evolutionary analysis of lowcarbon strategies based on the government-enterprise game in the complex network context," Journal of Cleaner Production, vol. 141, pp. 168-179, 2017.

[40] L. Wang and J. Zheng, "Research on low-carbon diffusion considering the game among enterprises in the complex network context," Journal of Cleaner Production, vol. 210, pp. 1-11, 2018.

[41] X. Zha, L. Ren, Y. Zhang, and G. Wan, "Evolutionary game analysis on the behavior strategies of power producers in renewable portfolio standard," Energy, vol. 162, pp. 505-516, 2018.

[42] C. Booth and T. Richardson, "Placing the public in integrated transport planning," Transport Policy, vol. 8, no. 2, pp. 141-149, 2001.

[43] S. G. Bagaeen, "Redeveloping former military sites: competitiveness, urban sustainability and public participation," Cities, vol. 23, no. 5, pp. 339-352, 2006. 